\title{
High Temperature Vacuum Annealing and Hydrogenation Modification of Exfoliated Graphite Nanoplatelets
}

\author{
Xiaobing Li, ${ }^{1,2}$ Sanjib Biswas, ${ }^{1,3}$ and Lawrence T. Drzal ${ }^{1}$ \\ ${ }^{1}$ The Composite Materials and Structures Center, Department of Chemical Engineering and Materials Science, \\ Michigan State University, 2100 Engineering Building, East Lansing, MI 48824, USA \\ ${ }^{2}$ Department of Civil Engineering, University of Mississippi, 106 Carrier Hall, University, MS 38677, USA \\ ${ }^{3}$ Engineering and Process Science, The Dow Chemical Company, Midland, MI 48674, USA
}

Correspondence should be addressed to Lawrence T. Drzal; drzal@egr.msu.edu

Received 14 January 2013; Accepted 31 July 2013

Academic Editor: Jong M. Park

Copyright (C) 2013 Xiaobing Li et al. This is an open access article distributed under the Creative Commons Attribution License, which permits unrestricted use, distribution, and reproduction in any medium, provided the original work is properly cited.

\begin{abstract}
Highly active defect sites on the edges of graphene automatically capture oxygen from air to form various oxygen groups. A two-step procedure to remove various oxygen functional groups from the defect sites of exfoliated graphene nanoplatelets (GNPs) has been developed to reduce the atomic oxygen concentration from $9.5 \%$ to $4.8 \%$. This two-step approach involves high temperature vacuum annealing followed by hydrogenation to protect the reduced edge carbon atoms from recombining with the atmospheric oxygen. The reduced GNPs exhibit decreased surface resistance and graphitic potential-dependent capacitance characteristics compared to the complex potential-dependent capacitance characteristics exhibited by the unreduced GNPs as a result of the removal of the oxygen functional groups present primarily at the edges. These reduced GNPs also exhibit high electrochemical cyclic stability for electrochemical energy storage applications.
\end{abstract}

\section{Introduction}

Graphene can be considered a polycyclic aromatic hydrocarbon [1-4]. The basal plane consists of $\mathrm{sp}^{2}$-hybridized carbon atoms in a honeycomb lattice structure [1-4]. However, the size of the basal plane of graphene is finite, and some of the carbon atoms in the highly aromatic basal plane terminate at the edges in a nonaromatic state. The carbon atoms present at the edges are highly chemically active as compared to the chemically inert carbon atoms present in the basal plane $[5,6]$. During the preparation of graphene nanosheets, the edge carbon atoms can react spontaneously with atmospheric oxygen to create carboxyl, keto, or hydroxyl group [5-7].

GNPs developed by the Drzal research group in Michigan State University are prepared by acid intercalation and rapid exfoliation process in a microwave environment. The acidintercalated graphite particles undergo substantial expansion to form worm-like products, which are then mechanically grounded to generate small stacks of graphenes that are 1 to 15 nanometers thick, with diameters ranging from submicrometer to 100 micrometers. The size of the resulting GNPs can be further reduced to a few hundred nanometers by vibratory ball milling over extended period of a few days. The exfoliation process and morphologies of GNPs are detailed elsewhere [7]. The exfoliation process minimizes the presence of basal plane defects so that the number of edge sites is fixed for a given platelet size. Surface analysis indicates a proportional increase in the atomic oxygen concentration with decreasing graphene nanosheets dimension $[8,9]$. For large GNPs with an average lateral dimension $15 \mu \mathrm{m}$ and surface area around $270 \mathrm{~m}^{2} / \mathrm{g}$, the oxygen atomic concentration is less than $5 \%[8,9]$. However, for small GNPs with an average dimension less than $500 \mathrm{~nm}$ and surface area close to $550 \mathrm{~m}^{2} / \mathrm{g}$, the oxygen atomic concentration increases to about $10 \%[8,9]$. The edge chemical composition is important for dispersion in various media as well as for electron transport between graphene nanosheets when they are dispersed in polymers or used by themselves in bulk applications.

Application of GNPs of variable sizes for enhanced supercapacitor electrode performance was presented earlier $[8,9]$. 
It was shown that the incorporation of large GNPs enhanced the electronic charge transport within the bulk macroscopic configuration for high power supercapacitor electrode applications $[8,9]$. However, the hydrophobicity of the large area aromatic basal plane often restricts the wetting and dispersion of the aqueous-based electrolytes inside the bulk electrode. It has been demonstrated earlier that the incorporation of smaller GNPs with higher edge oxygen content relative to the basal plane area provides better wettability of the electrode to facilitate ionic electrolyte transport [8]. The increase in the specific capacitance can be attributed to increased specific surface area and the presence of oxygen functional groups at the nanosheet edges. The presence of oxygen functional groups significantly enhances the specific capacitance from the change in the oxidation states at different applied electrode potentials $[10,11]$. At the same time, the changing potential can cause the reversible transformation of different oxidation states of the surface functional groups to alter the potential capacitance relation significantly [10-13]. In comparison to the large aromatic basal plane area in larger GNPs, the smaller nanosheets are therefore expected to exhibit a complex potential capacitance relation due to the presence of highly surface active oxygen content $[12,13]$. The complex potential capacitance relationship also affects the performance of electrodes for electrochemical capacitor applications. The increasing edge chemical functionalities introduce a series of contact resistances over the large microscopic areas causing a significant voltage drop during the discharge of the capacitors at high current densities.

Therefore, it is worth of investigating the removal of oxygen groups on GNPs. But the removal of oxygen from the edge defect sites is completely different from that for removal of oxygen on the basal plane, which has been extensively studied earlier in the reduction of graphite oxide (GO) $[3,14-16]$. Few results have been published specifically addressing the reduction of oxygen on the edges of graphene nanosheets. Chemical approaches are useful to reduce oxygen functionalities and convert GO back to graphene using hydrazine [14-16], sodium borohydride $\left(\mathrm{NaBH}_{4}\right)$ [17], and hydroquinone [18]. Simple high temperature annealing of GO has also been reported [14]. GO was also exfoliated and reduced by rapid heating to high temperature (up to $1050^{\circ} \mathrm{C}$ ) to produce graphene nanosheets [19]. However, all of these approaches still leave residual oxygen content of about 8 atomic\% or higher. The residual oxygen is likely concentrated on the defect sites. Also, simple thermal annealing of GO at temperatures of 1000 to $1100^{\circ} \mathrm{C}[14,20]$ could only produce graphene with $\sim 7$ atomic\% of oxygen, and the resulting reduced GO exhibits electronic properties inferior to pristine graphene [14] as suggested by Park and Ruoff [19].

The reduction of oxygen on graphenes has been extensively focused on GO wherein the improvement in conductivity is due to the increased fraction of $\mathrm{sp}^{2}$ carbon atoms after the reduction treatment. These carbon atoms are on the basal plane, and the enhanced electrical conductivity is mainly within individual graphene sheets [14]. Alternatively graphene nanosheets of 3-5 $\mathrm{nm}$ thicknesses can be produced by nonreactive approaches, such as microwave-assisted exfoliation of acid-intercalated graphite or ball milling of natural graphite [19], wherein the harsh oxidation reaction responsible for the generation of basal plane defects is avoided. However, oxygen functional groups are always detected because defect sites inevitably exist on the edges. Even the as-received graphite contains a few percent of oxygen. Little information can be found on the removal of $\mathrm{O}$-groups from the edges of graphene nanosheets. Treatment of pristine graphene nanosheets with hydrazine and hydroquinone under various conditions in our laboratory did not show any result of reduction. Akhavan [20] thermally annealed GO, but analysis showed that the surface still retained 7 atomic\% of oxygen. Most likely this is a result of the reaction of active carbon edge sites with the atmospheric oxygen to regenerate the oxygen functional groups at the edges. Therefore, it is crucial to passivate the edge carbon atoms to reduce the oxygen content at the defect sites of graphene nanosheets.

In this study, we report a two-step process in which submicron GNPs were vacuum-annealed at high temperature $\left(550^{\circ} \mathrm{C}\right)$ to remove oxygen groups from the defect sites, and then the defect sites were capped with hydrogen atoms in the temperature range of $100-250^{\circ} \mathrm{C}$ to prevent the rapid graft of oxygen groups converted from oxygen source in air upon exposure to normal ambient environment. The hydrogen atoms came from the dissociation of $\mathrm{H}_{2}$ in a mixture of argon $(97$ vol $\%)$ and hydrogen $(3 \mathrm{vol} \%)$ under $800^{\circ} \mathrm{C}$. The electronic properties of the treated graphene nanosheets were investigated.

\section{Experimental}

2.1. Materials and Methods. GNPs of about $500 \mathrm{~nm}$, surface area of $510-540 \mathrm{~m}^{2} / \mathrm{g}$ were prepared from microwaveassisted exfoliation of acid-intercalated graphite and sizereducing ball milling in which the slurry of exfoliated GNPs/isopropanol and milling balls were vigorously vibrated in a sealed steel container for few days. The simple annealing experiments took place in the quartz tube (inner diameter: $\sim 8 \mathrm{~mm}$ ) reactor described in Figure 1. The process began with a pump/purge cycle using argon to remove any residual oxygen. Next, the reactor was evacuated to a pressure of less than $2.7 \mathrm{~Pa}$, and the temperature was raised to $550 \pm 5^{\circ} \mathrm{C}$ and for $30 \mathrm{~min}$. After vacuum annealing, the tube was flushed with Ar, cooled to room temperature, sealed (via V2) and then transferred in an argon glove box (oxygen below $20 \mathrm{ppm}$, $\mathrm{H}_{2} \mathrm{O}$ below $2 \mathrm{ppm}$ ). Two XPS samples were prepared from the annealed GNPs. The first one was transferred under Ar atmosphere, and the second was exposed to air prior to loading into the XPS chamber.

The vacuum annealing and hydrogenation were carried out in a $20 \mathrm{~mm}$ diameter quartz reactor as shown in Figure 2. Prior to the experiment, the temperature profile along the axial direction of the tube reactor was mapped under the conditions of $550-600 \mathrm{~mL} / \mathrm{min}_{2}$ (3 vol\%)/argon flow rate and the temperature of $800^{\circ} \mathrm{C}$ to determine where the GNPs were to be placed. After the sample was loaded, the system was sealed to outside air and flushed. Then, V2 and V4 were closed as shown in Figure 2(b). All the rest valves were open. 


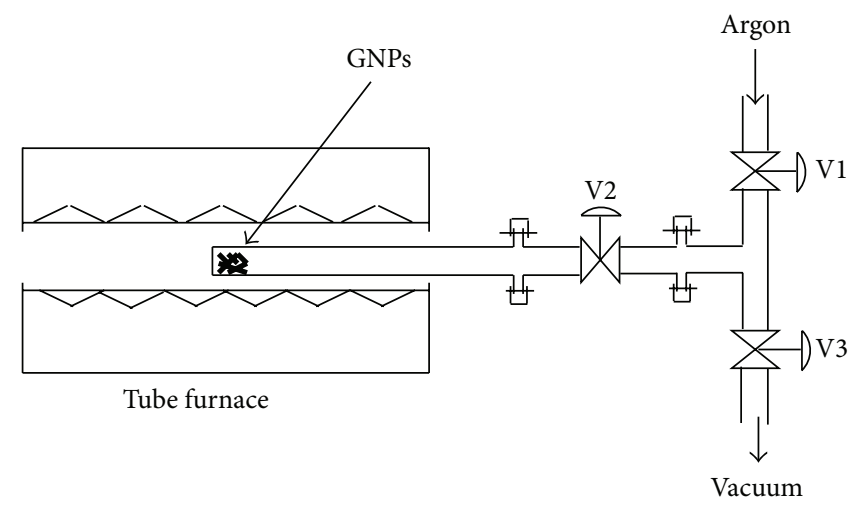

FIgURE 1: Direct vacuum annealing of GNPs.

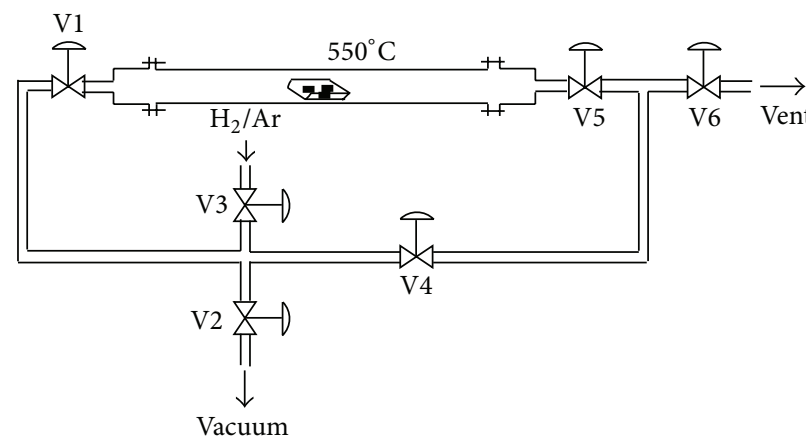

(a) Vacuum annealing

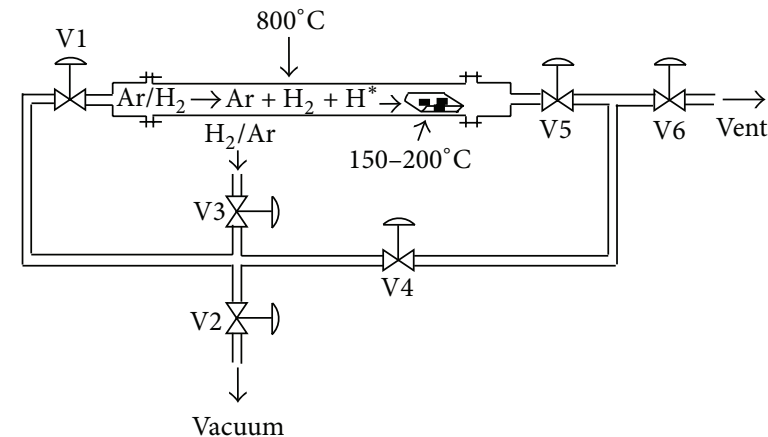

(b) Hydrogenation

Figure 2: Two-step treatment of GNPs.

The system was flushed with the same $\mathrm{H}_{2} / \mathrm{Ar}$ mixture to remove residual oxygen. Next, the reactor was evacuated, and the center of the tube reactor was heated to $550^{\circ} \mathrm{C}$ and kept isothermal for $30 \mathrm{~min}$.

After annealing, the sealed tube was tilted slightly to allow the graphene to move to the cooler region of the reactor, where temperature could be about $200^{\circ} \mathrm{C}$. The temperature at the center was increased to $800^{\circ} \mathrm{C}$ while keeping the $\mathrm{H}_{2}$ /argon flow rate at $550-600 \mathrm{~mL} / \mathrm{min}$. Hydrogenation was carried out in two steps, first at $200^{\circ} \mathrm{C}$ for $1 \mathrm{hr}$ followed by another $1 \mathrm{hr}$ at $150^{\circ} \mathrm{C}$. For hydrogenation at about $150^{\circ} \mathrm{C}$, the quartz boat with the graphene nanosheets was moved closer to the end of the tube reactor. Finally, heating was stopped, and the system was cooled to room temperature to remove the treated sample for characterizations.

The surface resistance of the film was measured using a standard four-point probe measurement from Keithley 2400 source meter. Graphene nanosheets were dispersed in isopropanol assisted by small tip sonication for 1-2 min to form slurry of graphene nanosheets/isopropanol. The specimens were prepared by spray coating of slurry of nanosheets/isopropanol on a rectangular glass substrate. Three different locations were chosen for each sample in the test.

2.2. Instrument. The thermogravimetric analyzer (TGA), Q50 from TA Instruments, New Castle, DE, USA, was used to determine the weight loss for both the reduced and the unreduced samples. The analysis was carried out at $5^{\circ} \mathrm{C} / \mathrm{min}$ heating rate in air.

In the Raman spectroscopy characterization, a Horiba Jobin Yvon LabRAM Aramis Raman Spectrometer with a $532 \mathrm{~nm}$ laser was used. The laser diameter used in our experiment was $10 \mu \mathrm{m}$, which was large enough to include the edges of $500 \mathrm{~nm}$ graphene nanosheets within the bulk sample to exhibit a pronounced disorder or defect induced D-band peak near $1340 \mathrm{~cm}^{-1}$ wavelength. Eight different locations were selected in the test.

The X-ray photoelectron spectroscopy (XPS) analysis was carried out with a magnesium $\mathrm{K} \alpha \mathrm{X}$-ray source in Perkin Elmer Phi 5400 ESCA system at pressure between $1.33 \times 10^{-6}$ and $1.33 \times 10^{-5} \mathrm{~Pa}$ with pass energy of $29.35 \mathrm{eV}$ and a take-off angle of $45^{\circ}$.

2.3. Potential Capacitance Analysis. The potential capacitance analysis was carried out in a two electrode configuration with the area and loading of the active electrode materials in the counter electrode kept much higher than working electrode for the measurement. A $0.1 \mathrm{M} \mathrm{NaF}$ aqueous solution was used for all the potential capacitance analysis. For electrochemical stability analysis, the two electrode configuration was used with equivalent loading of active material on both electrodes. The loading of GNPs was close to $4 \mathrm{mg} / \mathrm{cm}^{2}$. 


\section{Results and Discussion}

Since exceptionally high temperature may damage graphene samples and too low temperature may not be sufficient to remove oxygen groups at the defect sites, we vacuum $(2.7 \mathrm{~Pa})$ annealed GNPs at $550^{\circ} \mathrm{C}$ referring to the work of Ihm et al. [21], in which carbon nanotubes were annealed at $500^{\circ} \mathrm{C}$ under high-vacuum $\left(2.7 \times 10^{-5} \mathrm{~Pa}\right)$ for $30 \mathrm{~min}$ to remove oxygen completely.

The condition for hydrogenation is important as well. Dinger et al. [22] found that $\mathrm{CH}$ armchair groups and $\mathrm{CH}$ zigzag groups on the edge of graphite layer decomposed at $327^{\circ} \mathrm{C}$ and $377^{\circ} \mathrm{C}$, respectively. Therefore, hydrogenation of graphene nanosheets only occurs in a certain temperature range which we found to be $100-250^{\circ} \mathrm{C}$, and this is consistent with the above published results. In this study, the heat treated sample was hydrogenated for $1 \mathrm{hr}$ at $200^{\circ} \mathrm{C}$ and $1 \mathrm{hr}$ at $150^{\circ} \mathrm{C}$, respectively.

In order to prove the need to passivate edge carbons with hydrogen, a simple annealing of the GNPs was performed. After vacuum annealing of GNPs, half of the sample was transferred to a stainless steel vessel in an argon glove box in which oxygen was kept below 20 ppm. A sealed transfer vessel was used to move the sample to an XPS system without exposure to the air. The other half of the treated sample was exposed to air under room temperature for $24 \mathrm{hrs}$ before XPS analysis. A vacuum heat treated and hydrogenated sample (GNP-H) was also analyzed by XPS. Figure 3 displays the overall XPS scan of GNPs treated in different stage indicating relative concentrations of elements in each sample. The data in Table 1 shows that vacuum annealing at $550^{\circ} \mathrm{C}$ for $30 \mathrm{~min}$ can reduce oxygen to a very low level of 2.1 atomic\%. However, after exposure to air even under ambient conditions, the oxygen level increased close to its original level. The annealing followed by the hydrogenation and then exposure to the atmosphere resulted in a reduction of surface oxygen content by $\sim 50 \%$ to 4.78 atomic $\%$ of oxygen concentration. The limitation in further reduction in oxygen might be the result of physical events. The outermost GNPs had full access to the reducing and hydrogenation environment, but not all of the GNPs in the bulk graphene stack were sufficiently exposed to the reducing atmosphere during the experiment, as shown in Figure 4.

The deconvolution of C1s XPS signal provides important information on the changes in the carbon molecular state. Mattevi et al. [14] reported the thermal annealing of GO in vacuum or in argon $/ \mathrm{H}_{2}$ atmosphere in the temperature range of $500-600^{\circ} \mathrm{C}$ to effectively increase the $\mathrm{sp}^{2}$ fraction by reducing the $\mathrm{sp}^{3}$ content after the removal of oxygen functional groups. The deconvolution of the $\mathrm{Cl}$ s peak showed carbon in six different chemical bond environments: $\mathrm{C}=\mathrm{C} / \mathrm{C}-$ $\mathrm{C}$ aromatic ring at $284.6 \mathrm{eV}$; the asymmetrical envelope corresponding to damaged alternate hydrocarbon with $\mathrm{sp}^{3}$ radical near $\sim 285.4 \mathrm{eV}$; the carbonyl group $\mathrm{C}-\mathrm{O}$ at $286.1 \mathrm{eV}$; the keto $\mathrm{C}=\mathrm{O}$ at $287.5 \mathrm{eV}$; the carboxylic acid group $\mathrm{O}=\mathrm{C}-\mathrm{OH}$ at $289.2 \mathrm{eV}$; and a broad $\pi-\pi^{*}$ near 290.6 to $291.4 \mathrm{eV}[14,23$, 24]. However, annealing above $600^{\circ} \mathrm{C}$ resulted in only a slight increase in graphitic carbon [14]. Similar analyses of carboncarbon and carbon-oxygen bonds were reported for GO
TABLE 1: Oxygen concentrations of graphene nanosheets after treatment.

\begin{tabular}{lc}
\hline Sample & Oxygen conc. (atomic\%) \\
\hline GNP & 9.49 \\
GNP annealed without exposure to air & 2.14 \\
GNP annealed then exposed to air & 7.97 \\
GNP-H & 4.78 \\
\hline
\end{tabular}

reduced by $\mathrm{NaBH}_{4}$ [17]. The C1s regions for the above three treated samples in our experiment revealed the molecular nature of carbon and $\mathrm{C}-\mathrm{O}$ bonds as seen Figure 5 and in Table 2. The $\mathrm{C} / \mathrm{O}$ atomic ratio for the unreduced sample was 12.7 but increases to 23.2 for the reduced sample indicating the reduction of various oxygen functional groups. The peak intensity analysis gives a clear indication of the reduction of oxygen functional group containing carbon atoms to $\mathrm{sp}^{3}$ and $\mathrm{sp}^{2}$ hybridized $\mathrm{C}-\mathrm{H}$ bonds. The increase in the $\mathrm{sp}^{2}$ content of the sample with the increase in the intensity ratio of the aromatic $\mathrm{C}=\mathrm{C} / \mathrm{C}-\mathrm{C}$ peak at $284.6 \mathrm{eV}$ relative to the damaged alternate $\mathrm{C}-\mathrm{H}$ bonded $\mathrm{sp}^{3}$ peak near $285.5 \mathrm{eV}$ for the reduced sample reveals the successful conversion of $\mathrm{sp}^{3}$ bonded carbons to $\mathrm{sp}^{2}$ state. This is also confirmed by the increase in the $\mathrm{sp}^{2}$ content from the aromatic $\mathrm{C}=\mathrm{C} / \mathrm{C}-\mathrm{C}$ peak at $284.6 \mathrm{eV}$ to the peaks associated with different oxygen functional groups at 286.1, 287.5, and $289.2 \mathrm{eV}$, respectively. While annealing increased the concentration of $\mathrm{sp}^{2}$ carbon, it appeared that the carbon atoms at the defect sites were highly unstable and actively captured oxygen from the environment at room temperature if exposed to the air. Interestingly, hydrogenation retained the improved $\mathrm{sp}^{2} \mathrm{C}$ content gained in annealing in which some $\mathrm{sp}^{3} \mathrm{C}$ atoms were removed. The three oxygen groups were effectively reduced through the combination of annealing/hydrogenation, especially when compared with GNPs sample which was vacuum annealed then exposed to air. $\mathrm{C}-\mathrm{O} / \mathrm{C}-\mathrm{O}-\mathrm{C}$ and $\mathrm{O}-\mathrm{C}=\mathrm{O}$ were kept at very low level even if the sample was allowed to contact with the air after hydrogenation, which is consistent with the overall oxygen content in Table 1 . However, the $\mathrm{sp}^{2}$ fraction is not very high because the size of graphene nanosheets in this study was very small (around $500 \mathrm{~nm}$ ). Mattevi et al. [14] reported that an $\mathrm{sp}^{2}$ fraction of about $85 \%$ for reduced GO could substantially improve electrical conductivity approaching that of pristine graphene. Our opinion is that it also depends on the size of graphene under investigation. Smaller platelets obviously possess more defect sites.

Thermogravimetric analysis (TGA) in Figure 6 shows that the reduced sample displays enhanced thermal stability with more than $98 \%$ weight retention up to at least $400^{\circ} \mathrm{C}$. The unreduced sample on the other hand showed more than $10 \%$ weight loss near $400^{\circ} \mathrm{C}$. The increasing stability of the reduced sample could be attributed to two factors. First, the vacuum annealing treatment at $550^{\circ} \mathrm{C}$ for 30 minutes could remove residual amorphous carbon from the sample. Second, replacing the edge oxygen content such as the keto or carboxylic acid functional group with increasing $\mathrm{sp}^{2}$ fraction 


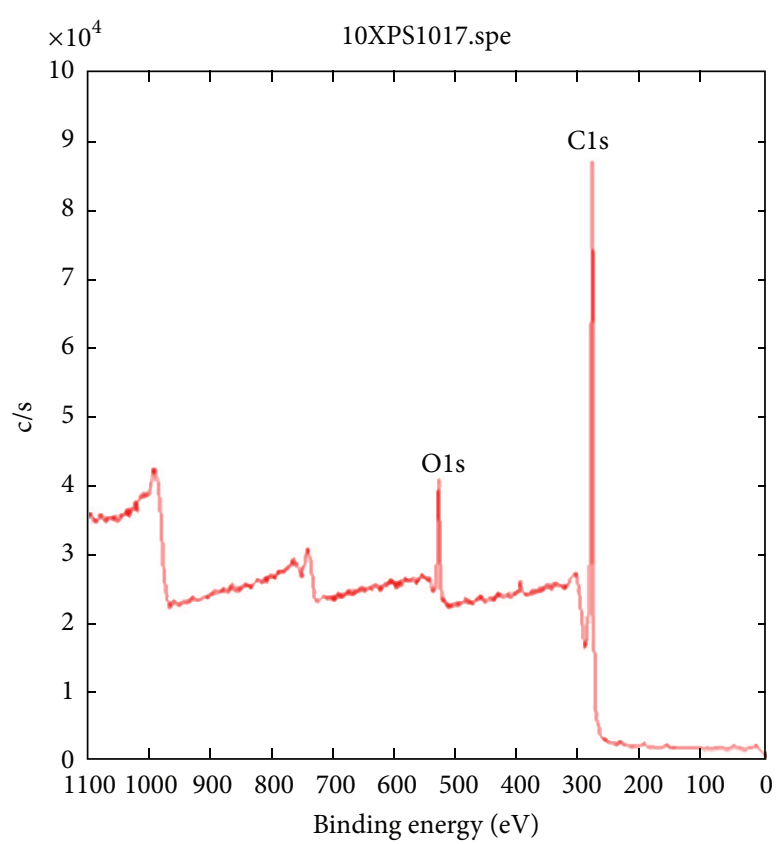

(a)

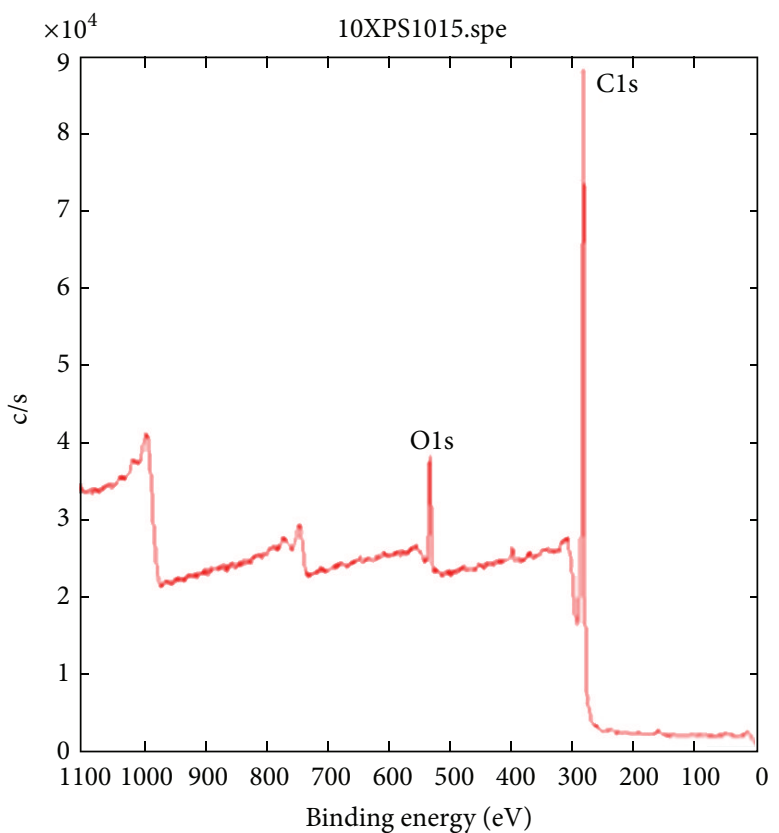

(c)

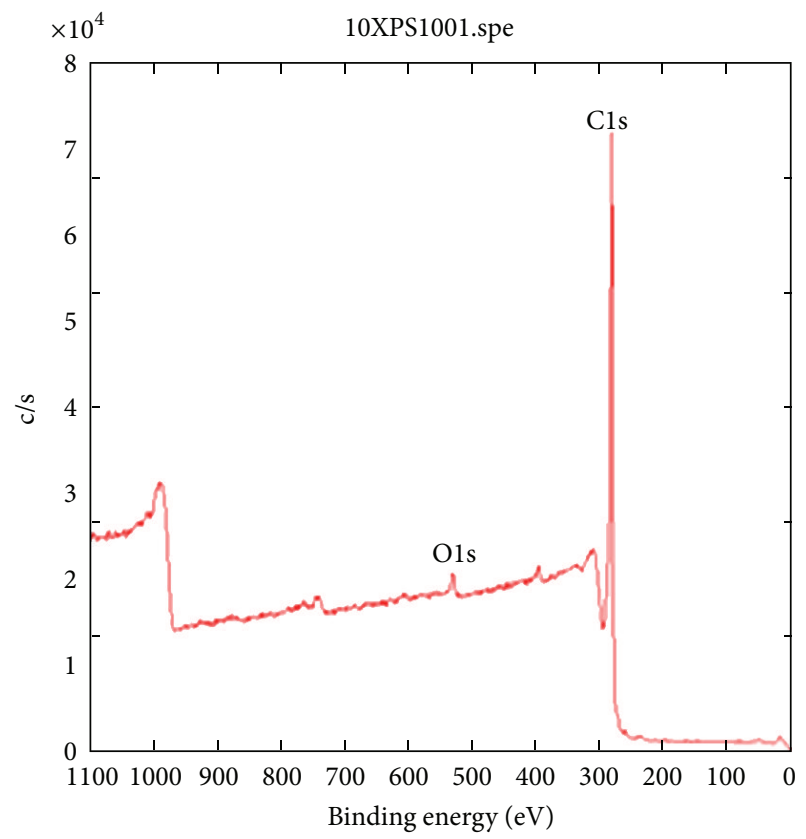

(b)

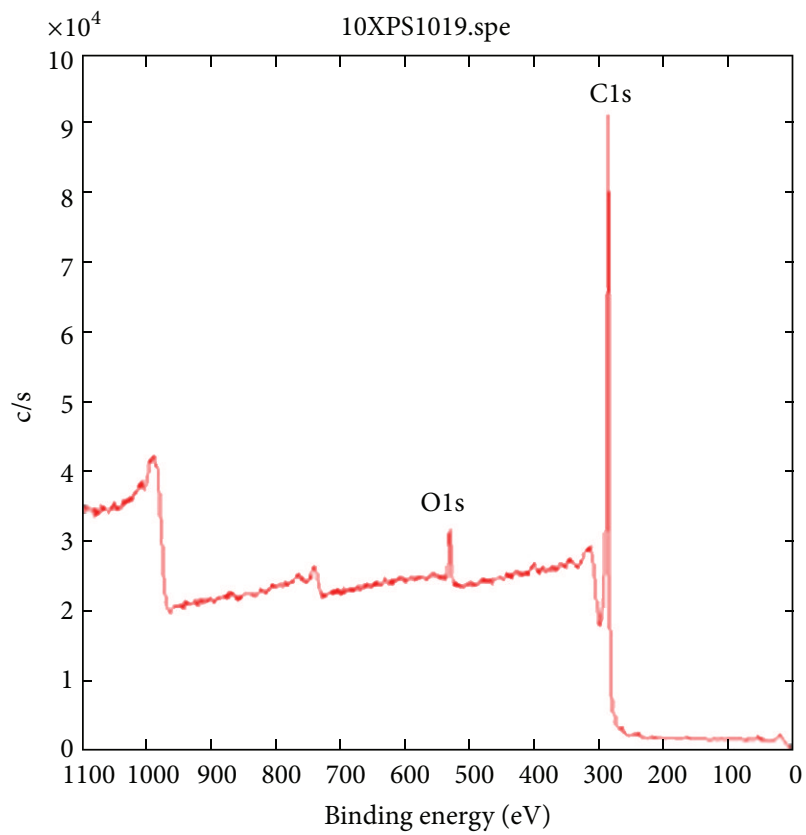

(d)

FIGURE 3: XPS elemental scan of GNPs. (a) GNPs; (b) GNPs annealed without exposure to air; (c) GNPs annealed then exposed to air; (d) GNPs annealed then hydrogenated.

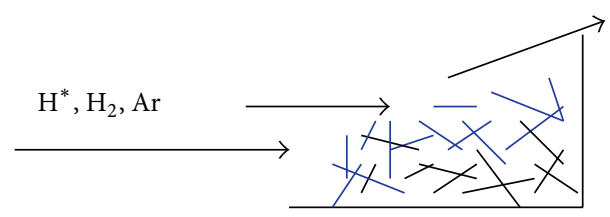

FIGURE 4: GNPs reduction treatment under continuous flow of Hydrogen/argon. at the edges imparted higher thermal stability without the generation of decomposition products like $\mathrm{CO}$ or $\mathrm{CO}_{2}[25$, 26].

Typical Raman spectra for GNP and GNP-H are compared in Figure 7, and the results are summarized in Table 3. No pronounced shift in positions of D-band peak and Gband peak indicates that the two-step treatment did not cause damage to the aromatic character of these nanosheets. It is well documented that the intensity ratio of the G-band 


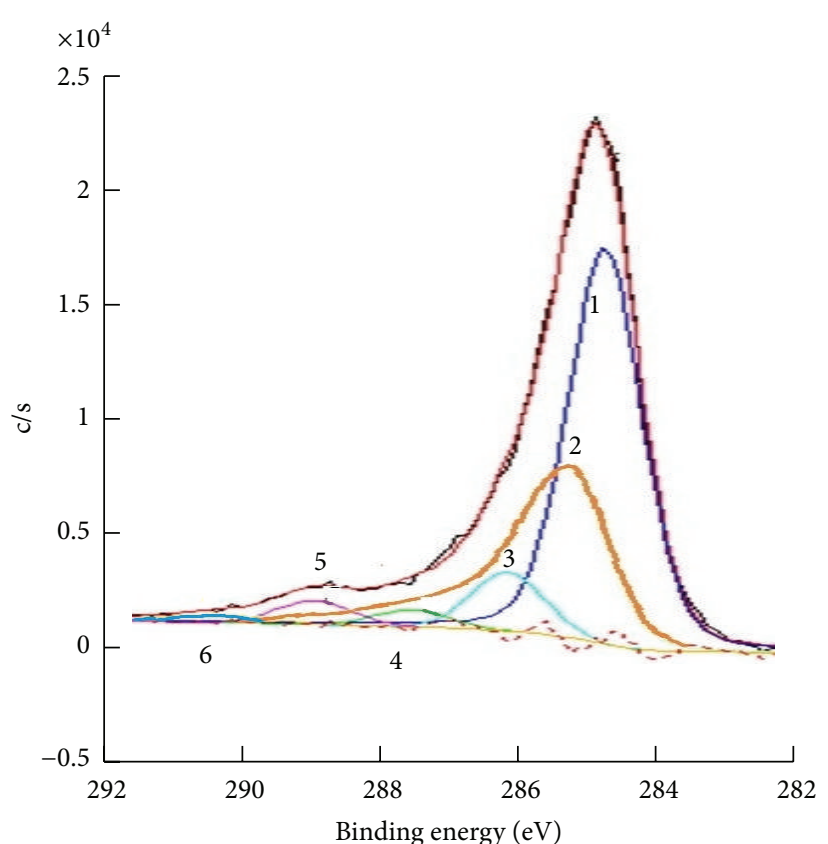

(a)

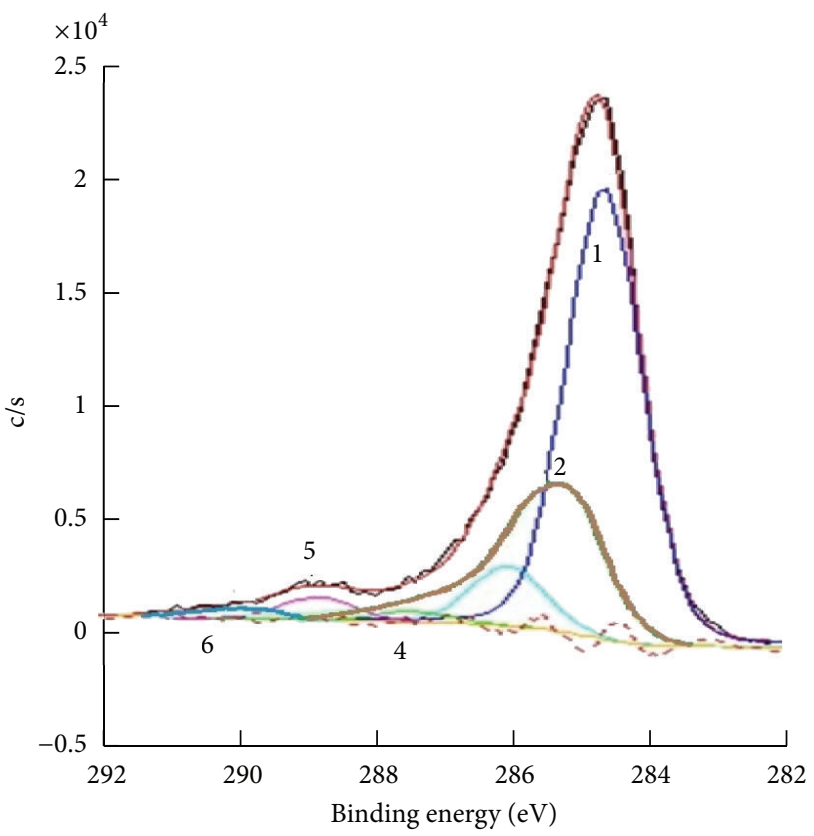

(c)

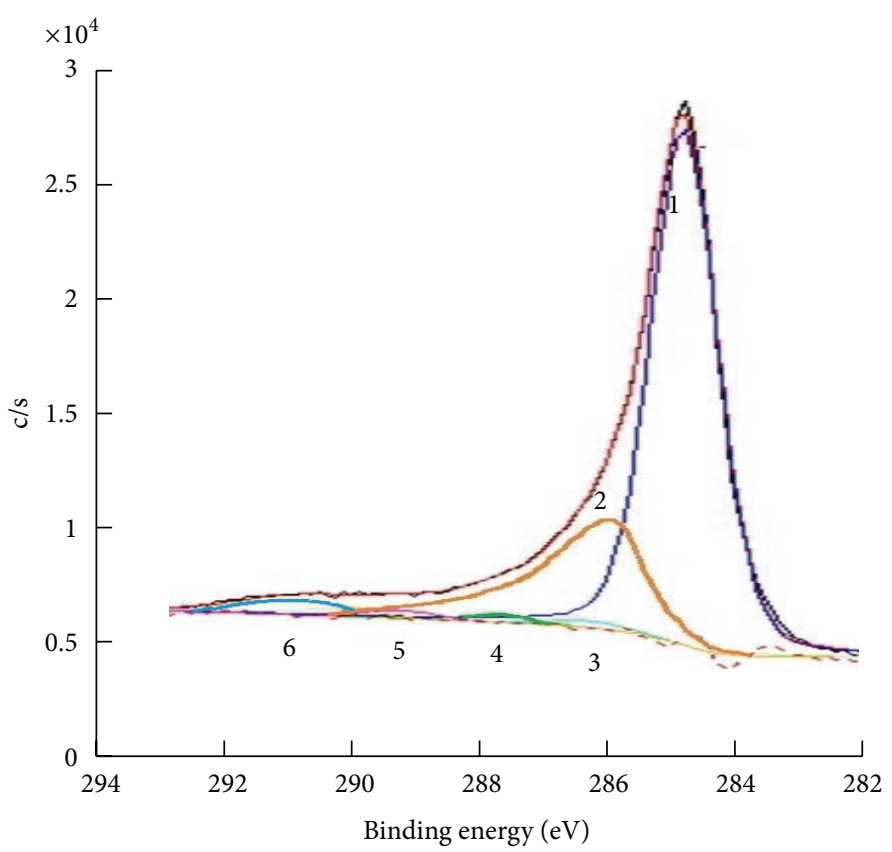

(b)

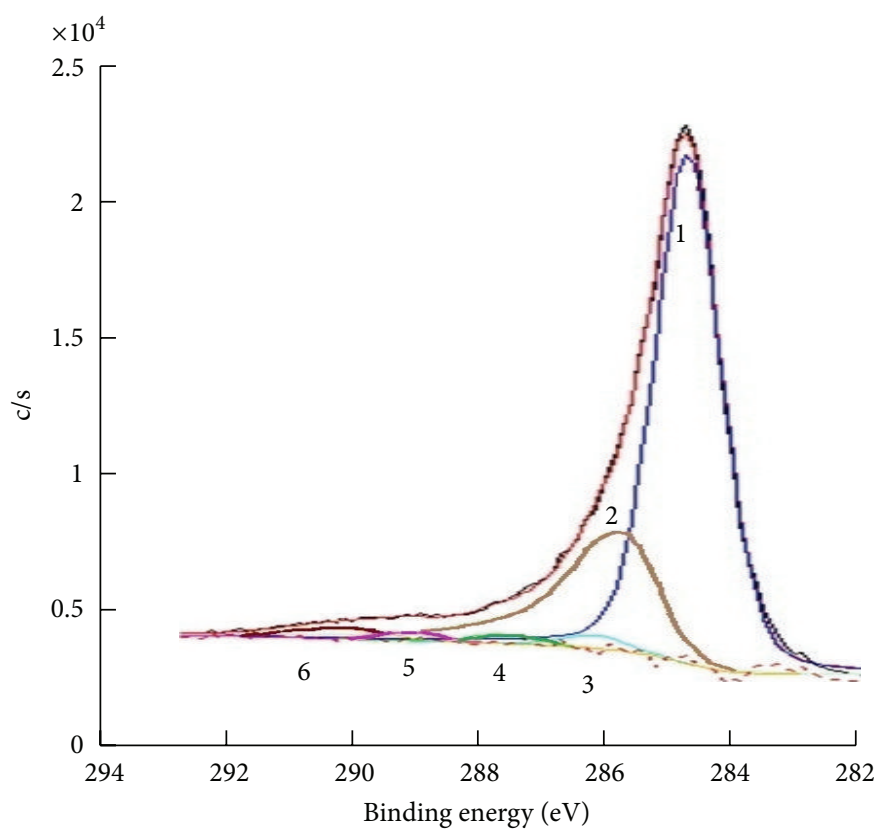

(d)

FIGURE 5: The C1s peaks in the XPS spectra of GNPs. (a) GNP; (b) GNP annealed without exposure to air; (c) GNP annealed then exposed to air; (d) GNP annealed then hydrogenated.

peak to the defect or disorder oriented D-band peak is an indication about the aromatic purity of the graphene basal plane $[27,28]$. Even for the pure graphitic sample, the Dband is expected to be present from the termination of aromatic continuity of the basal plane by the $\mathrm{sp}^{3}$ hybridized edge area with the presence of oxygen functional groups $[27,28]$. In our study, the small increase in the G-band to the "defect and disorder" D-band intensity ratio for the reduced sample as compared to the unreduced sample indicates the removal of amorphous carbon during the vacuum annealing treatment.

A decrease in the sheet resistance is expected with the reduction of nanosheets as reported in the literature $[10,12]$. The measured surface resistance was $7.28 \mathrm{kohm} / \mathrm{sq}$ for GNPs and $3.56 \mathrm{kohm} / \mathrm{sq}$ for the reduced GNP-H, indicating almost $50 \%$ decrease in the surface resistance. There might be three mechanisms responsible for the improved conductivity: (1) in-plane conductivity of individual GNPs was increased 
TABLE 2: The Cls peak position and the relative atomic percentage of various functional groups, corresponding to the deconvoluted peaks in Figure 5 .

\begin{tabular}{|c|c|c|c|c|c|c|}
\hline \multirow{3}{*}{ Material } & \multicolumn{6}{|c|}{ Cls subpeak binding energy $(\mathrm{eV})$ (bond-allocated carbon concentration (atomic\%)) } \\
\hline & 1 & 2 & 3 & 4 & 5 & 6 \\
\hline & $\mathrm{sp}^{2} \mathrm{C}$ & $\mathrm{sp}^{3} \mathrm{C}$ & $\mathrm{C}-\mathrm{O} / \mathrm{C}-\mathrm{O}-\mathrm{C}$ & $\mathrm{C}=\mathrm{O}$ & $\mathrm{O}-\mathrm{C}=\mathrm{O}$ & $\pi-\pi^{*}$ \\
\hline GNP & $284.68(53.87)$ & $285.22(32.75)$ & $286.18(7.14)$ & $287.68(2.01)$ & $289.18(2.93)$ & $290.67(1.30)$ \\
\hline GNP annealed, no exposure to air & $284.79(69.44)$ & $285.95(24.83)$ & $286.29(0.81)$ & $287.79(0.88)$ & $289.29(0.98)$ & $290.83(3.06)$ \\
\hline GNP annealed then exposed to air & $284.78(59.23)$ & $285.45(27.79)$ & $286.28(7.25)$ & $287.78(1.29)$ & $289.28(2.76)$ & $290.53(1.67)$ \\
\hline GNP-H & $284.74(69.63)$ & $285.80(24.51)$ & $286.24(1.61)$ & $287.74(1.05)$ & $289.24(1.05)$ & $290.39(2.16)$ \\
\hline
\end{tabular}

TABLE 3: Raman spectroscopy results for treated and untreated samples.

\begin{tabular}{lccc}
\hline Sample & D-band peak position $(1 / \mathrm{cm})$ & G-band peak position $(1 / \mathrm{cm})$ & Intensity D/G $(\%)$ \\
\hline GNP & $1338.6 \pm 1.7$ & $1568.2 \pm 1.2$ & $41 \pm 3.5$ \\
GNP annealed then exposed to air & $1337.4 \pm 3.8$ & $1567.1 \pm 1.2$ & $42 \pm 6.1$ \\
GNP-H & $1338.1 \pm 3.6$ & $1567.2 \pm 1.2$ & $36 \pm 8.7$ \\
\hline
\end{tabular}

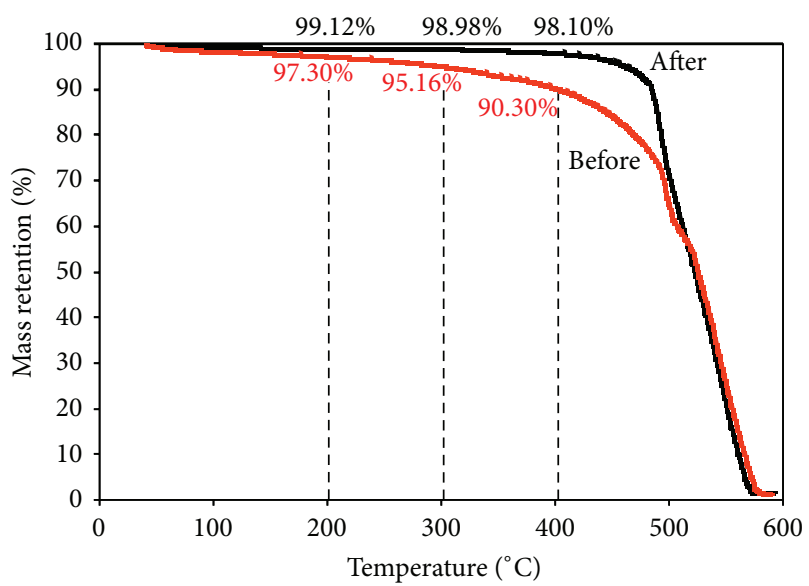

FIGURE 6: Thermogravimetric analysis of GNPs before and after annealing/hydrogenation.

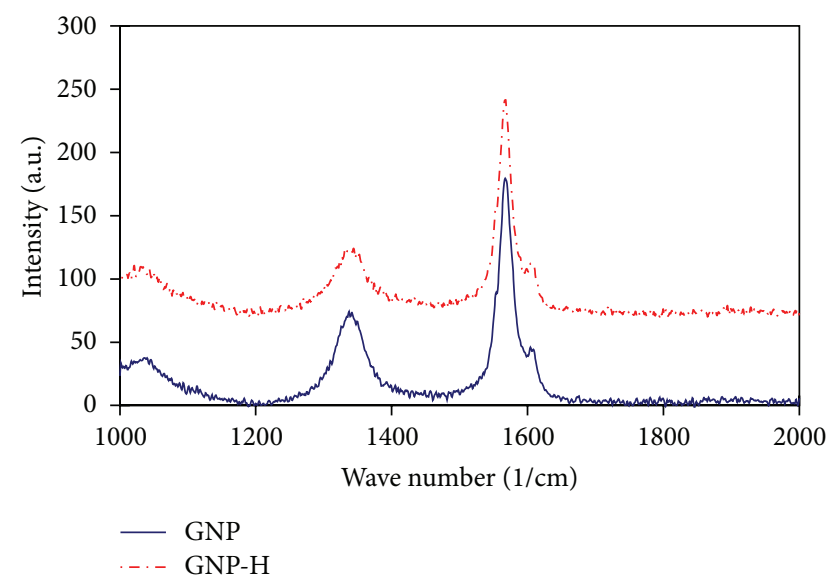

FIGURE 7: Raman spectroscopy spectra of unreduced (GNP) and reduced GNPs (GNP-H). by the generation of larger fraction of $\mathrm{sp}^{2}$ carbon upon reduction, (2) there were fewer oxygen groups at the defect sites to bind electrons moving in GNPs plane, (3) fewer large oxygen functional groups anchored at the defect sites led to less distortion of the GNP packing such that the transport of electrons among graphene nanosheets was enhanced. In our investigation, oxygen functional groups, primarily present at the edges of GNPs, functioned as an insulator to impede the transport of electrons among graphene nanosheets. The replacement of oxygen groups with hydrogen atoms at least had some role to play in the above mechanisms (2) and (3) because hydrogen is less electronegative than oxygen and the size of hydrogen atom is much smaller than that of an oxygen group. It is evident from Table 2 that the increased $\mathrm{sp}^{2}$ carbon content also contributed to a better electrical conductivity. Note that the reduction in electrical resistance was $51 \%$, not in magnitude which is seen normally for reduced GO [17]. The reason is that GO has only less than 15 atomic\% $\mathrm{sp}^{2}$ carbon [17]; therefore, there is substantial improvement in electrical conductivity upon reduction treatment of GO. However, reduced GO cannot out-perform the pristine graphene nanosheets [14], whereas our two-step treated graphenes further doubled the electrical conductivity compared with the pristine graphene.

The potential-dependent capacitance characteristics of the electrodes prepared from small nanosheets in the reduced and unreduced state was determined to investigate the effect of the oxygen functional groups at the edges. The typical potential capacitance characteristics for large area graphene basal plane exhibit a linear increase on both sides of the potential of zero charge (PZC) as reported earlier for the basal plane of highly oriented pyrolytic graphite [29-32].

As shown in Figure 8(a), the small unreduced GNPs exhibited much higher capacitance and a complex potential dependence of capacitance over the same potential range. This could be the results of the effect of increased surface area, porosity, and the edge oxygen functional groups resulting 


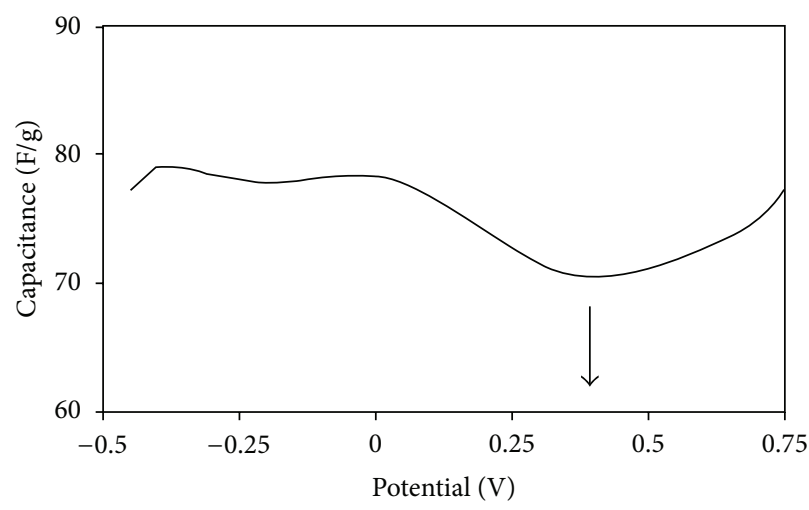

(a)

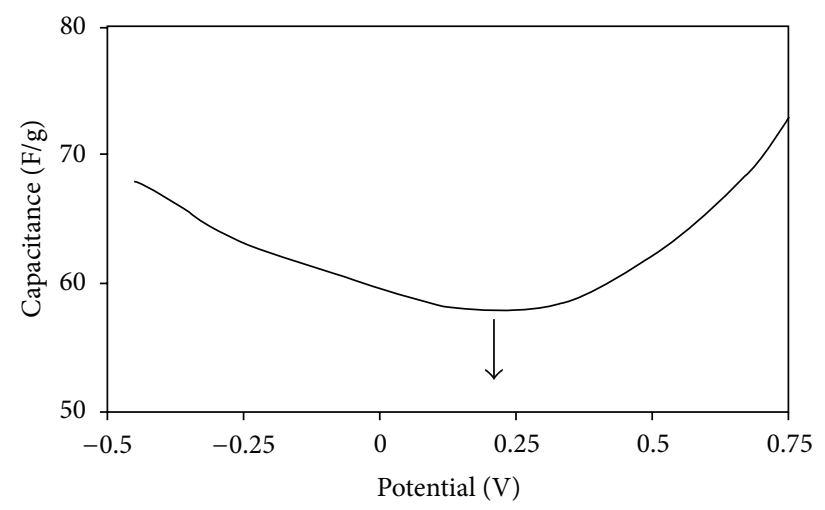

(b)

FIGURE 8: Potential capacitance characteristics. Capacitance measured at different applied potential in $0.1 \mathrm{M}$ NaF aqueous solution for different materials, (a) unreduced, (b) reduced GNPs.

from going from large to small nanosheets [14, 29-32]. The oxygen functional groups contribute to the increasing capacitance from the reversible change in the oxidationreduction state with the solvated electrolyte ions [32]. The complex potential capacitance behavior also originated from the changing oxidation state at different potentials. The occurrence of the broad and nearly flat band potential capacitance characteristics for the unreduced GNPs was possibly a result of the redistribution of charges in the presence of surface functional groups at the edges as compared to the larger and inert basal plane area for the larger graphene nanosheets [32].

After reduction, the specific capacitance decreased as compared to the unreduced state. Interestingly, the complex potential capacitance relation recovered the parabolic characteristics with a broad potential minimum near the PZC as shown in Figure 8(b). A decrease in the specific capacitance is expected from the reduced contribution to the capacitance from the reduction of oxygen functional groups $[14,29-32]$. The reductive process also led to the recovery of parabolic shape of the response curve implying greater graphitic characteristics of the system. However, the clear shift in the potential minima away from the PZC was possibly due to the contribution of remaining surface active oxygen functional groups as was found for the larger nanosheets.

From the above results, we conclude that the presence of oxygen functional groups at the edges of GNPs affects the potential capacitance characteristics and the specific capacitance of the electrode. With reduction, the specific capacitance decreases, and the parabolic potential capacitance characteristics are recovered.

The electrochemical stabilities of the electrodes were compared in a two-electrode configuration for the unreduced and the reduced GNPs. Without the addition of any binder material, the dispersion of nanosheets was stirred overnight in isopropanol, and the slurry was then evenly spread on a stainless steel current collector and dried at $80^{\circ} \mathrm{C}$ under vacuum to remove any remaining solvent. The electrodes were then assembled with a cellulose paper separator in a two-electrode configuration which was tightened and immersed in $6 \mathrm{M}$ aqueous $\mathrm{KOH}$ solution for electrochemical characterization. A galvanostatic constant current technique was used to characterize the charge-discharge characteristics of these electrodes at $1 \mathrm{~A} / \mathrm{g}$ discharge current density.

As shown in Figures 9(a) and 9(b), the control sample exhibited a voltage drop (IR drop) of $\sim 200 \mathrm{mv}$ at the vertex potential during the discharge cycle. The voltage drop remained almost constant with increasing discharge cycle number from the 50th to 1000th cycles. As shown in Figures 9(c) and 9(d), for the hydrogenated sample, the initial voltage drop was close to $200 \mathrm{mv}$, which decreased to $75 \mathrm{mv}$ with increasing cycle number from 50th to 1000th cycle. For the hydrogenated sample, this could be explained by the nanosheet wettability. With the reduction of oxygen functional groups, the hydrophobicity of the small graphene nanosheets increased and thereby reducing the wettability of the electrode to limit the ease of aqueous electrolytic diffusion to the mesoporous network inside the bulk electrode. With increasing electrochemical cycles, the electrode wettability improved to reduce the voltage drop from 200 to $75 \mathrm{mv}$. Thus, the rate capability for the hydrogenated electrode was enhanced with increasing cycle number. The higher electrical conductivity of the hydrogenated GNPs could also be another factor for better rate capability of the electrode.

\section{Summary and Conclusion}

In this investigation, small graphene nanosheets with a high edge oxygen concentration were vacuum annealed $\left(550^{\circ} \mathrm{C}\right)$ and hydrogenated $\left(150-200^{\circ} \mathrm{C}\right)$ to reduce the atomic oxygen content from 9.5 to 4.8 atomic\%. Exposure of the vacuum annealed sample to air was found to be responsible for the spontaneous repopulation of the edge sites upon exposure to atmospheric oxygen. Hydrogenation of the vacuum annealed sample is therefore essential to keep the active edge sites largely immune from the recombination with atmospheric oxygen. XPS analysis clearly revealed an equivalent increase in the $\mathrm{sp}^{2}$ content of the reduced sample from the unreduced state in which the oxygen functional groups were present 


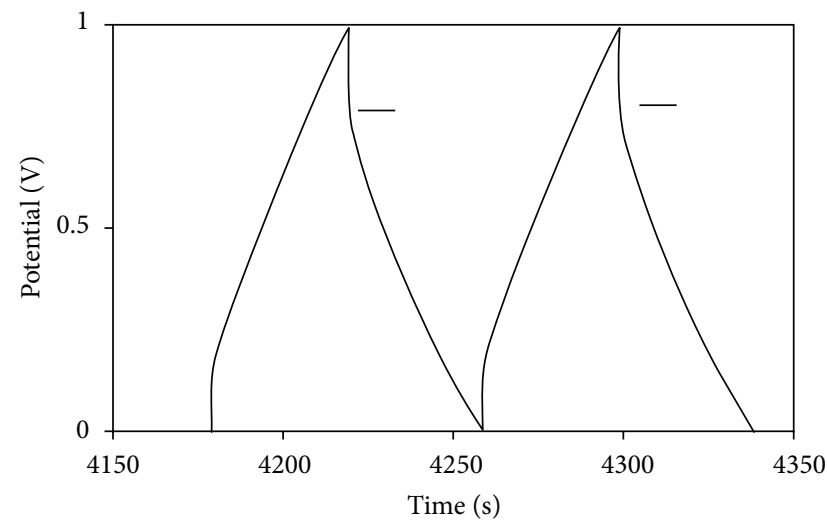

(a)

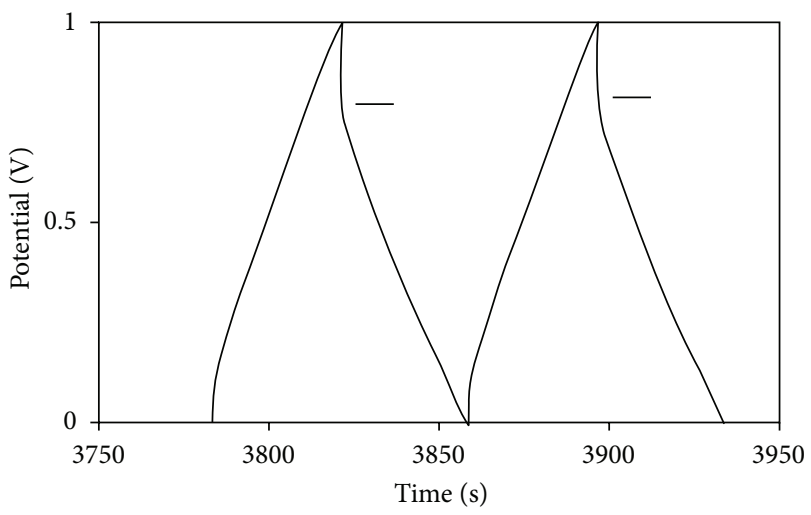

(c)

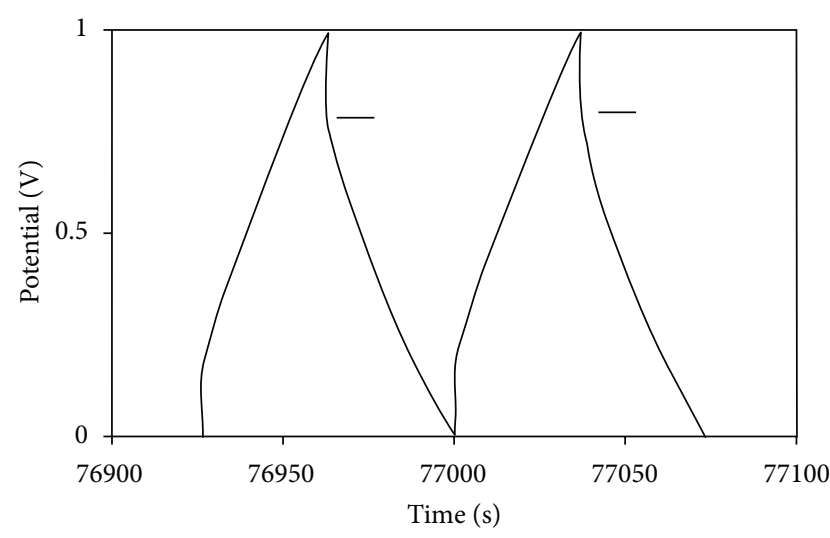

(b)

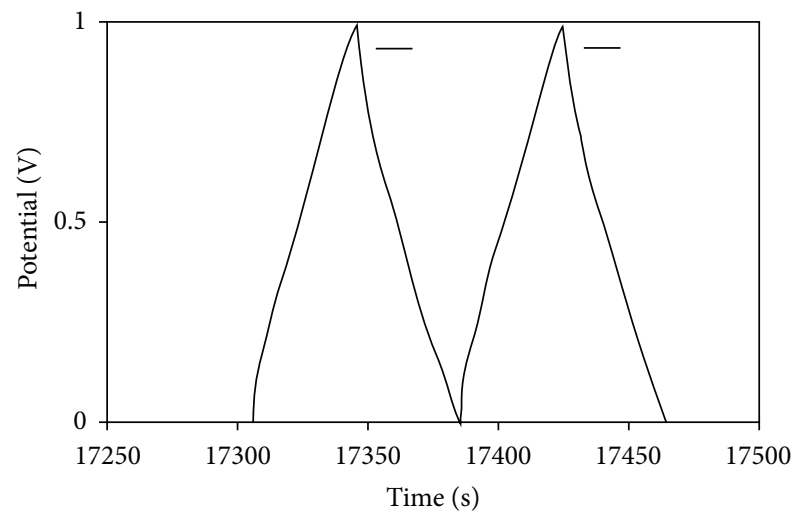

(d)

FIGURE 9: Constant current charge discharge characteristics of GNPs-based electrodes at $1 \mathrm{~A} / \mathrm{g}$ discharge current density. ((a), (b)) chargedischarge characteristics of unreduced GNPs at 50th and 1000th cycles and ((c), (d)) charge-discharge characteristics of reduced GNPs at 50th and 1000th cycles.

before the two-step reduction process. The hydrogenated sample was thermally, stable and the surface resistance decreased by almost $50 \%$ as a result of the reduced edge to edge interparticle resistance due to the reduction of oxygen functional groups. The decrease in edge oxygen content was also evidenced by the recovery of parabolic potential capacitance characteristics for the hydrogenated sample as compared to the unreduced sample. The unreduced sample on the other hand exhibited a complex potential capacitance relation from the reversible oxidation-reduction process associated with the oxygen functional groups primarily present at the edge defect sites. The hydrogenated sample demonstrated better stability with increasing electrochemical cycles for electrochemical capacitor applications.

\section{Acknowledgments}

The authors thank Dr. Per Askeland for the XPS analysis, Dr. Inhwan Do for providing graphene sample, and Brian Rook for assistance in routine experiments throughout this investigation. They are staff members at the Composite Materials and Structures Center, Michigan State University.

\section{References}

[1] A. K. Geim and K. S. Novoselov, "The rise of graphene," Nature Materials, vol. 6, no. 3, pp. 183-191, 2007.

[2] M. J. Allen, V. C. Tung, and R. B. Kaner, "Honeycomb carbon: a review of graphene," Chemical Reviews, vol. 110, no. 1, pp. 132145,2010

[3] C. N. R. Rao, A. K. Sood, K. S. Subrahmanyam, and A. Govindaraj, "Graphene: the new two-dimensional nanomaterial," Angewandte Chemie, vol. 48, no. 42, pp. 7752-7777, 2009.

[4] A. K. Geim, "Graphene: status and prospects," Science, vol. 324, no. 5934, pp. 1530-1534, 2009.

[5] J. H. Warner, F. Schäffel, M. H. Rümmeli, and B. Büchner, "Examining the edges of multi-layer graphene sheets," Chemistry of Materials, vol. 21, no. 12, pp. 2418-2421, 2009.

[6] T. Enoki, Y. Kobayashi, and K.-I. Fukui, "Electronic structures of graphene edges and nanographene," International Reviews in Physical Chemistry, vol. 26, no. 4, pp. 609-645, 2007.

[7] H. Fukushima, Graphite reinforcements in polymer nanocomposites [Ph.D. thesis], Department of Chemical Engineering and Materials Science, Michigan State University, East Lansing, Mich, USA, 2003.

[8] S. Biswas and L. T. Drzal, "Multilayered nano-architecture of variable sized graphene nanosheets for enhanced supercapacitor electrode performance," ACS Applied Materials and Interfaces, vol. 2, no. 8, pp. 2293-2300, 2010. 
[9] S. Biswas and L. T. Drzal, "Multilayered nanoarchitecture of graphene nanosheets and polypyrrole nanowires for high performance supercapacitor electrodes," Chemistry of Materials, vol. 22, no. 20, pp. 5667-5671, 2010.

[10] S. Mitra and S. Sampath, "Electrochemical capacitors based on exfoliated graphite electrodes," Electrochemical and Solid-State Letters, vol. 7, no. 9, pp. A264-A268, 2004.

[11] M. D. Stoller, S. Park, Z. Yanwu, J. An, and R. S. Ruoff, "Graphene-based ultracapacitors," Nano Letters, vol. 8, no. 10, pp. 3498-3502, 2008.

[12] E. Conway, Electrochemical Supercapacitors: Scientific Fundamentals and Technological Applications, Plenum, New York, NY, USA, 1st edition, 1999.

[13] G. Lota, T. A. Centeno, E. Frackowiak, and F. Stoeckli, "Improvement of the structural and chemical properties of a commercial activated carbon for its application in electrochemical capacitors," Electrochimica Acta, vol. 53, no. 5, pp. 22102216, 2008.

[14] C. Mattevi, G. Eda, S. Agnoli et al., "Evolution of electrical, chemical, and structural properties of transparent and conducting chemically derived craphene thin films," Advanced Functional Materials, vol. 19, no. 16, pp. 2577-2583, 2009.

[15] V. C. Tung, M. J. Allen, Y. Yang, and R. B. Kaner, "Highthroughput solution processing of large-scale graphene," Nature Nanotechnology, vol. 4, no. 1, pp. 25-29, 2009.

[16] S. Stankovich, D. A. Dikin, R. D. Piner et al., "Synthesis of graphene-based nanosheets via chemical reduction of exfoliated graphite oxide," Carbon, vol. 45, no. 7, pp. 1558-1565, 2007.

[17] H.-J. Shin, K. K. Kim, A. Benayad et al., "Efficient reduction of graphite oxide by sodium borohydride and its effect on electrical conductance," Advanced Functional Materials, vol. 19, no. 12, pp. 1987-1992, 2009.

[18] A. B. Bourlinos, D. Gournis, D. Petridis, T. Szabó, A. Szeri, and I. Dékány, "Graphite oxide: chemical reduction to graphite and surface modification with primary aliphatic amines and amino acids," Langmuir, vol. 19, no. 15, pp. 6050-6055, 2003.

[19] S. Park and R. S. Ruoff, "Chemical methods for the production of graphenes," Nature Nanotechnology, vol. 4, no. 4, pp. 217-224, 2009.

[20] O. Akhavan, "The effect of heat treatment on formation of graphene thin films from graphene oxide nanosheets," Carbon, vol. 48, no. 2, pp. 509-519, 2010.

[21] K. Ihm, T.-H. Kang, D. H. Lee et al., "Oxygen contaminants affecting on the electronic structures of the carbon nano tubes grown by rapid thermal chemical vapor deposition," Surface Science, vol. 600, no. 18, pp. 3729-3733, 2006.

[22] A. Dinger, C. Lutterloh, J. Biener, and J. Küppers, "Hydrogen atom reactions with graphite island edges on $\mathrm{Pt}(111)$ surfaces: hydrogenation through Eley-Rideal and hot-atom processes," Surface Science, vol. 421, no. 1-2, pp. 17-26, 1999.

[23] D.-Q. Yang and E. Sacher, "Carbon is X-ray photoemission line shape analysis of highly oriented pyrolytic graphite: the influence of structural damage on peak asymmetry," Langmuir, vol. 22, no. 3, pp. 860-862, 2006.

[24] J. Filik, P. W. May, S. R. J. Pearce, R. K. Wild, and K. R. Hallam, "XPS and laser Raman analysis of hydrogenated amorphous carbon films," Diamond and Related Materials, vol. 12, no. 3-7, pp. 974-978, 2003.

[25] D. R. Dreyer, S. Park, C. W. Bielawski, and R. S. Ruoff, "The chemistry of graphene oxide," Chemical Society Reviews, vol. 39, no. 1, pp. 228-240, 2010.
[26] S. Park, J. An, R. D. Piner et al., "Aqueous suspension and characterization of chemically modified graphene sheets," Chemistry of Materials, vol. 20, no. 21, pp. 6592-6594, 2008.

[27] I. Calizo, A. A. Balandin, W. Bao, F. Miao, and C. N. Lau, "Temperature dependence of the raman spectra of graphene and graphene multilayers," Nano Letters, vol. 7, no. 9, pp. 26452649, 2007.

[28] K. N. Kudin, B. Ozbas, H. C. Schniepp, R. K. Prud'homme, I. A. Aksay, and R. Car, "Raman spectra of graphite oxide and functionalized graphene sheets," Nano Letters, vol. 8, no. 1, pp. 36-41, 2008.

[29] J. N. Barisci, G. G. Wallace, D. Chattopadhyay, F. Papadimitrakopoulos, and R. H. Baughman, "Electrochemical properties of single-wall carbon nanotube electrodes," Journal of the Electrochemical Society, vol. 150, no. 9, pp. E409-E415, 2003.

[30] J. Xia, F. Chen, J. Li, and N. Tao, "Measurement of the quantum capacitance of graphene," Nature Nanotechnology, vol. 4, no. 8, pp. 505-509, 2009.

[31] J.-P. Randin and E. Yeager, "Differential capacitance study on the basal plane of stress-annealed pyrolytic graphite," Journal of Electroanalytical Chemistry, vol. 36, no. 2, pp. 257-276, 1972.

[32] J.-P. Randin and E. Yeager, "Differential capacitance study on the edge orientation of pyrolytic graphite and glassy carbon electrodes," Journal of Electroanalytical Chemistry, vol. 58, no. 2, pp. 313-322, 1975. 

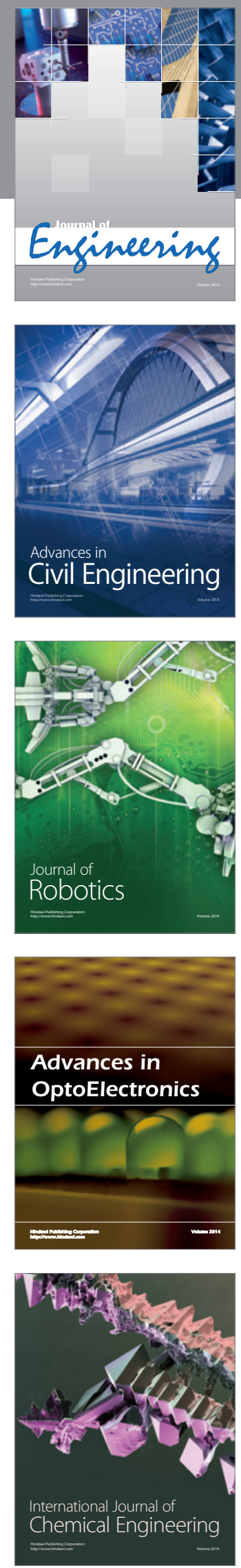

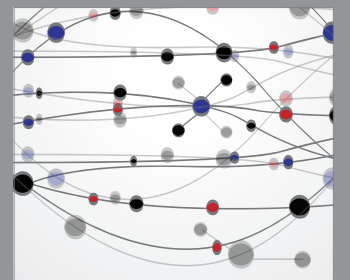

The Scientific World Journal
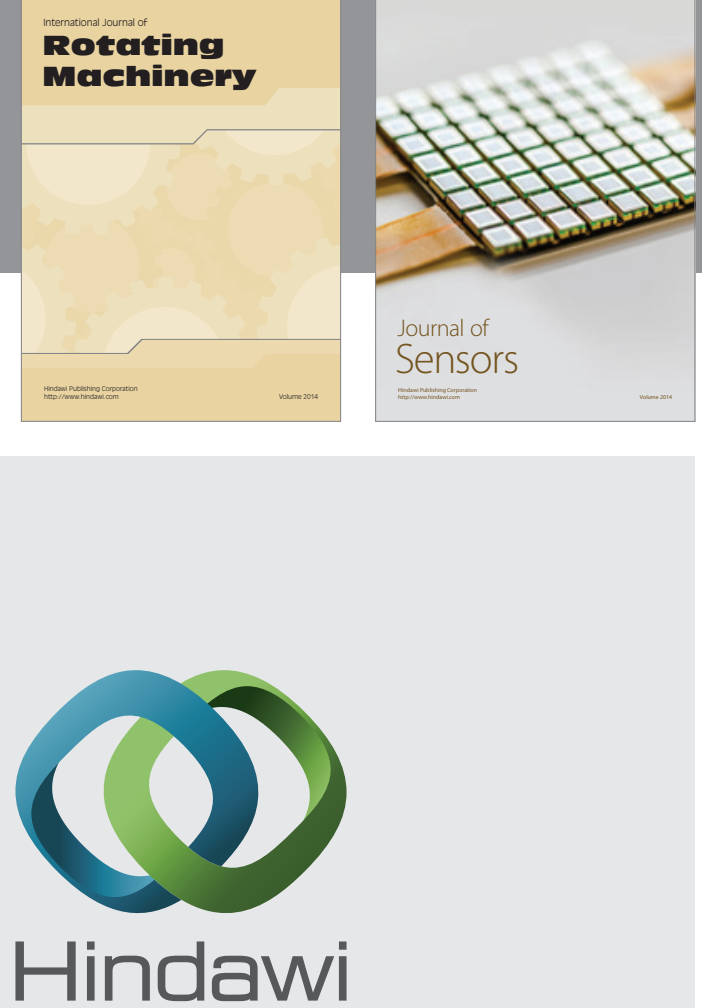

Submit your manuscripts at http://www.hindawi.com
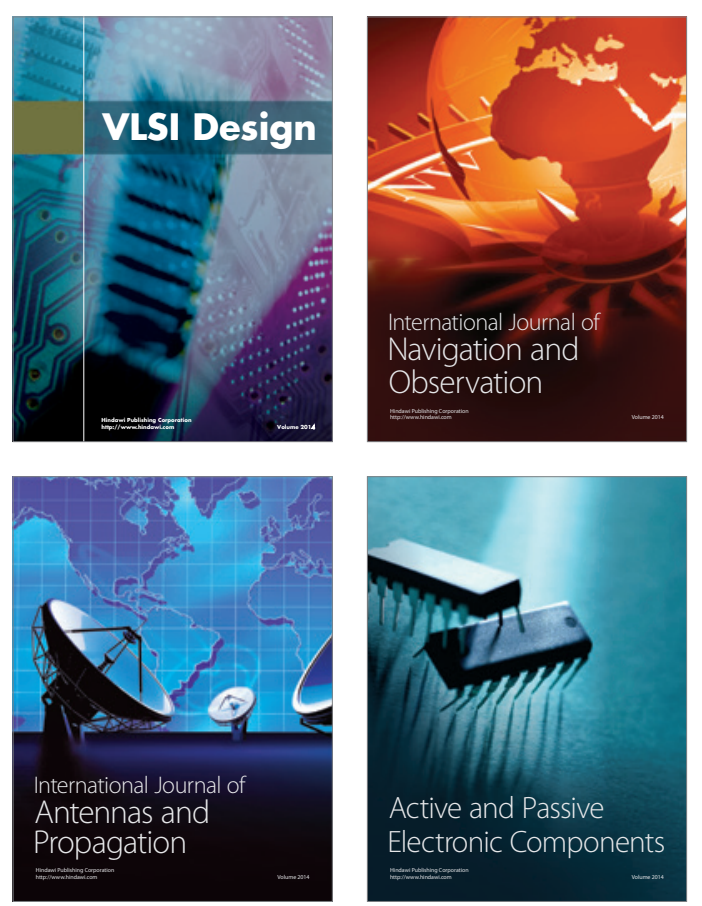
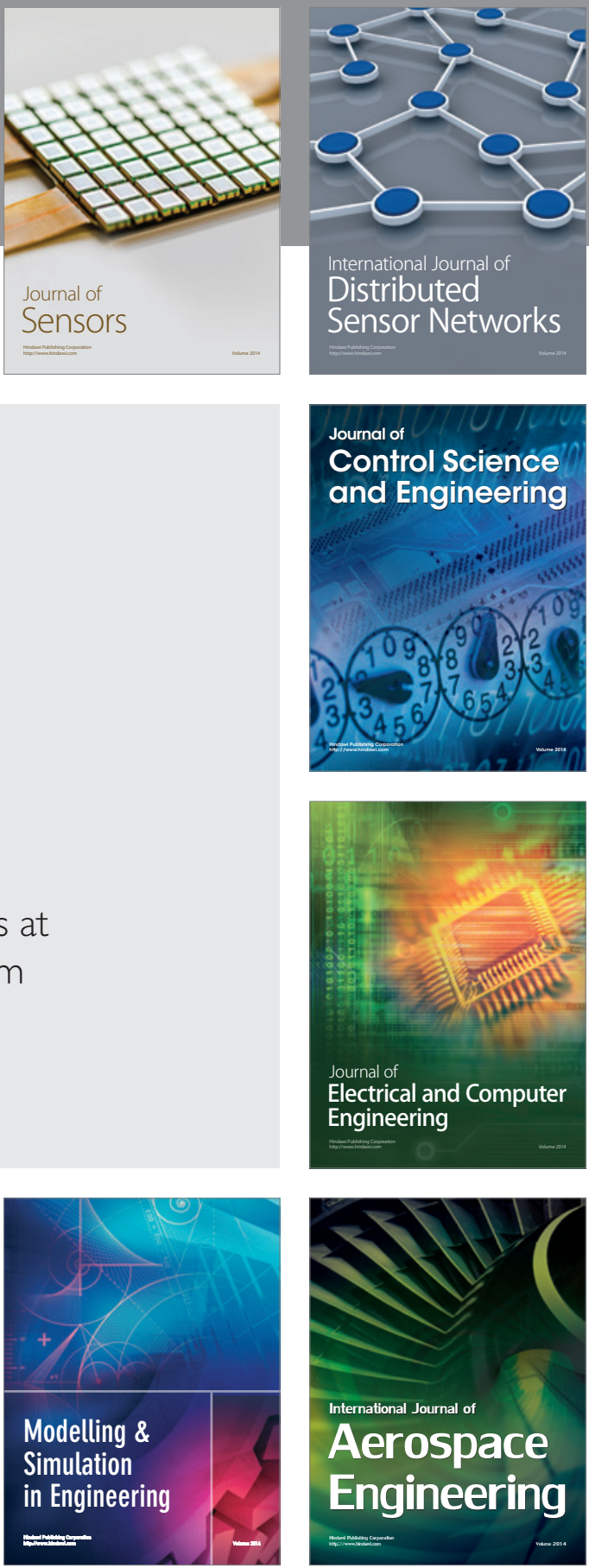

Journal of

Control Science

and Engineering
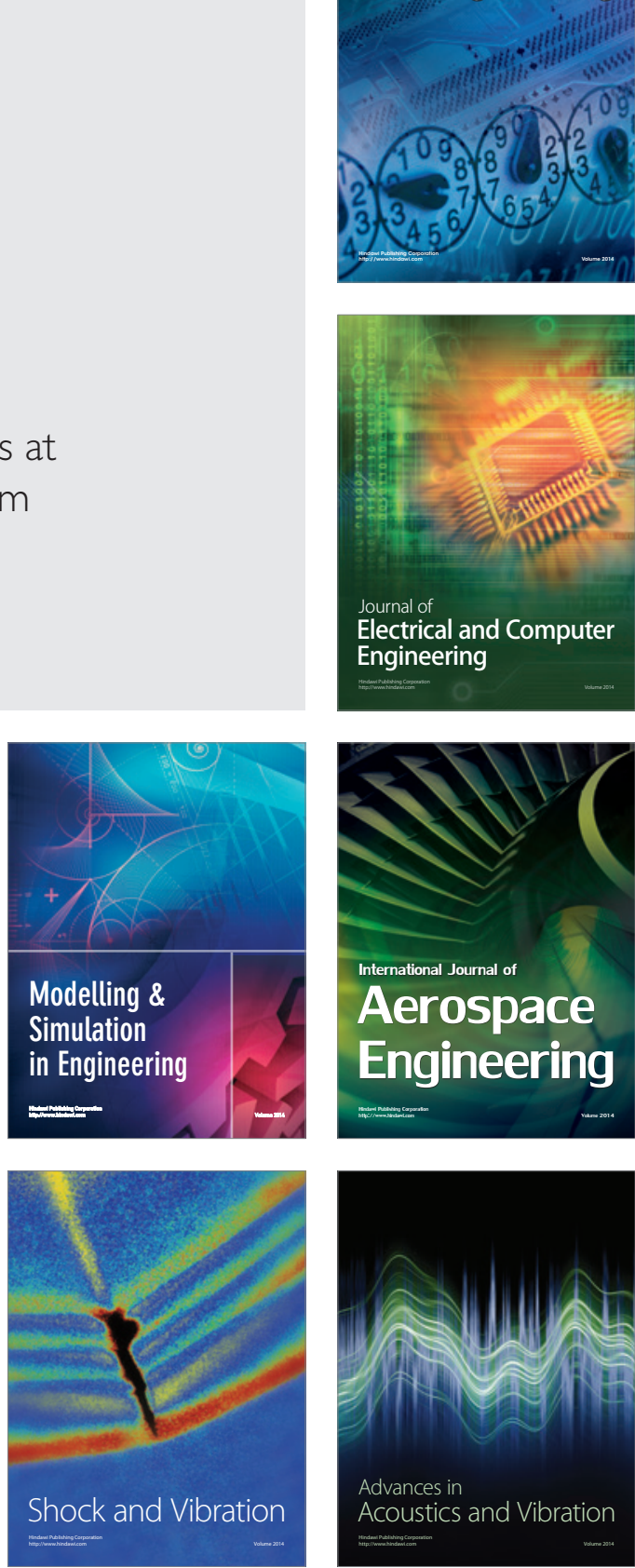